\section{THE AIMS OF MEDICINE:}

\author{
BEING PART OF
}

An Address delivered to the Graduates in Medicine of the University of Glasgow, May I 87 I.

By JOHN YOUNG, M.D., F.R.S.Ed., Professor of Natural History in the University.

IT seems a truism to tell you that the practice of medicine is not the application of rules, but is solely and entireiy the exercise of common sense. Chomel, whose treatise on pathology is well worthy of careful study, from the excellence of his method, says : "Medical art, or, as it is generally called, practical medicine, is only the application of common sense to the treatment of disease, and, consequently, to the preservation and the improvement of health. Common sense is thus, afterhonesty (vir probus), the first quality of the physician-nay, even of man, whatever his social position : knowledge of diseases, no less indispensable, holds in reality only the second place. This knowledge is within the reach of every man of ordinary intelligence if he give the time and take the trouble : common sense is not the portion of all."

With the subordination herein stated, I most cordially agree; but at the same time it must, be borne in mind that, while it is in every man's power to acquire the requisite amount of knowledge wherewith to start in practice, and, though your presence here as graduands indicates your possession of that knowledge, as well as of a certain amount of common sense in its application, the acquisition of this minimum qualification is a very small merit on your part. Mr. Ruskin says that every man can be taught to draw, though very few can become artists-few, that is to say, possess even that small amount of imagination which is needed for successful copying from nature. But in medicine it is different. There may be no harm in giving a man the power to spoil paper in the practice of what he may never come to do with decent skill; but the experiments of a medical man are of another sort : the disaster of a bad experiment is an injury to the community. The world cries out when a great statesman is bled to death for an inflammation of the lungs, or a great artist is killed by purgation in enteric typhus. The mistake is as great; but perhaps the results are more grievous when the labourer, the head of a family, is killed by similarly erroneous diagnosis or theoretical treatment. To diminish as far as possible the risk of incompetence of this sort is the object of the clinical examinations which you have just undergone. Some of you may be conscious of the imperfection of the test: let me remind you that the real test is one inapplicable by any medical board. Several weeks of observation would scarcely fulfil the conditions. But, though this defect is admitted, it is needless to remind you that the sole responsibility of your future merits or demerits does not rest with the board which certifies you as qualified, any more than the conferring of the degree, talisman-fashion, completes your intellectual outfit.

That this is the view of the medical faculty in this University, is seen from the fact that the thesis is now required of the candidates for M.D.; its preparation being, in theory, an evidence that the period between receiving the M.B. and the final degree has been spent in continued observation and study. It is only courteous to believe that the interval is so spent; but, nevertheless, some of my colleagues agree with me in regretting that the evidence is not more clear. Personally, I regret that what the thesis originally was has now passed away; that an essay, more or less carefully written, has been substituted for the disputations on themes selected by the candidate. It was not necessary that the propositions set forth should be original; it was not even necessary that they should be true : the discussion brought out the real knowledge of the candidate, and gave opportunity to the cultivated man, or to him in whom strong native intellect replaced high culture, to show what was in him. But I fear the custom has now merited, by lapse of time, the censure of "antiquated"; and, when once that condemnation has been pronounced, it is needless to attempt its reversal.

Accepting, then, the present necessity for the preparation of a written essay, I would urge upon those who hear me, and whose turn is yet to come for obtaining the higher degree, the importance of trying to vindicate for themselves a better position than that of mere compilers-a more satisfactory claim to honour than that of merely editing the statements of others.

Hitherto I have spoken only of professional study ; but, gentlemen, I should ill discharge my duty if I failed to remind you that your duties neither begin nor end with the performance, however skilful, of purely medical functions. I might go further, and say that the cure of disease or the repair of injury is not the highest duty you have to perform.
The prevention of disease, or, better still, the improvement of those evil social conditions to which so much of physical deterioration is due, these form the highest ambition of the physician. To fulfil this noble function, the doctor must be more than the strict technical definition of his office requires. He must qualify himself to act worthily the part of citizen. Do not think that by this I allude to any political action on your part. On the contrary, there is no one for whom I have so thorough a dislike as a political doctor. Wire-pullers, if I may use a convenient American phrase, are well aware that a medical constituency is the least reliable even among academic constituencies; and the evil repute which they have seems to me matter of satisfaction. Our profession is one which, of all others, tends to relieve us of the influence of authority : the very nature of its work throws us at every moment on our resources, and teaches us that kind of self-reliance which forbids, or, at least, if a man have any pith in him, renders difficult implicit obedience to any fixed code of opinions. And the more thoroughly a man fulfils the requirements of his profession, the less likely is he to degenerate into what I mean by a political doctor-that is, one who is content to surrender his individual opinions, and, accepting the platform of a party, to devote himself to their interests. I have heard a professional politician-though, I admit, not himself of great weight-speak slightingly of a distinguished surgeon, as a man of no political power. My indignant reply was, that he had not pretended to such a character; that if he had he would have done wrong, since he would thereby of necessity have been led to neglect his proper professional work, and that was his first object in life.

Within the walls of the University you have had a certain amount of political excitement : some of you have taken active part on one or other side. I would pray you to leave that behind you, as you leave other pastures, and to remember that hereafter life has more important duties than the support of Conservatives or Liberals as such. Far be it from me to ask you to cast off your political convictions, if you have any. What I mean is, that you should cease from active intervention on one side or other, for otherwise you endanger your usefulness to the community. Let me remind you of the description which I quoted at the beginning of the session, from Nathaniel Hawthorne, of the physician Roger Chillingworth. The source of his power lay in his not presenting any prominent individuality. You are not so ignorant of human nature as to be unaware of the fact that the bitterest and most lasting dislikes are those founded on political differences. It is enough, then, that you should act as your principles direct when the recording of your vote is a necessity. To do more, to act the part of an advocate, is to weaken your influence over a part of your constituents, and to weaken that influence is voluntarily to surrender an important part of your functions.

You are the teachers of the people ; you are their leaders in all matters of liberal policy in whichever party as currently designated the exercise of your political franchise enrols you. The Romish priests, when Rome was in the zenith of its glory, had not greater power than is in your hands, as the familiar visitors of the people, if only that power be discreetly exercised-if the wielder of that power fulfil the obligations which he has to day undertaken. Gentlemen, there is not one social question on which you cannot make your impress, if only you are qualified to counsel wisely. You may, under the influence of temporary excitement, or other less worthy motive, guide tre people to whom you have free access into a wrong course of action; but upon you will most undoubtedly fall the punishment if it be wrong. Success may for a time crown your efforts ; but disenchantment will come, and the power you once wielded for evil will be lost, and with it even the power to do good. Therefore, gentlemen, as a matter of self-interest, qualify yourselves to counsel wisely.

I would enforce this view of the medical man's duty by reference to one or two important social questions on which, it seems to me, the medical profession have it in their power to exercise much influence, and in regard to which, if they fail to exert their legitimate power, they incur a grave responsibility.

There is, as you are aware, much difference of opinion as to whether insanity is or is not on the increase. My own opinion, valeat quantum, is that increase is inevitable ; that the very material advancement of our civilisation has as an invariable-I will not say a necessary-consequence, that mental tension which, save under exceptionally favourable physical conditions, becomes aggravated by hereditary transmission into loss of control. But, even supposing that they are correct who deny the increase of this terrible disease, the fact still remains that it is not diminishing - that there is at any rate a constant quantity of insanity. To diminish the amount of disease as disease is your highest ambition : but insanity is not a merely medical question; it must be regarded also as a social question. A recent writer on the Scottish Poor-law has very clearly set forth the importance of insanity as a cause of pauperism ; and 
this, the heaviest drain on the community, comes therefore, to some extent at least, under your control. It comes in two ways ; first, because in your character of public teachers you have it in your power to alter, were it only a little, the evil customs which, by giving rise to physical degeneration, prepare the way for mental disturbance ; second, because as physicians you may in many cases avert the progress of ailments which would inevitably end in insanity, however obscure the chain of causation may be.

You are all aware, doubtless, of the history of recent opinion concerning insanity. You have heard of the barbarisms, not tolerated but actually enjoined by a profession which, in common with the philosophers, held insanity to be a perversion of the will, to be a punishable offence, for which whipping, seclusion, and other forms of torture were the suitable rewards. It is impossible in short compass to do justice to the gradual evolution of more rational opinions. Suffice it that more humane treatment was at first adopted, notwithstanding that erroneous psychology held undisputed sway; and that to-day still greater improvements have been introduced into the management of the insane as a consequence of the fuller recognition of mental disturbance as a symptom of physical disorder. Formerly, insanity was a dispensation of Providence, a sign of Divine vengeance, which was a matter of shame, the evidence of which was to be got out of sight as speedily as possible. To dream of averting it would have been held as a sign of an impious spirit, seeking to fly in the face of the decrees of Heaven. Now, the warding off of insanity is not only a question freely discussed, but the failure of the medical profession to avert it more frequently is, and in the future will be still more, regarded as matter of blame.

But before that happy time comes, when our success in this direction shall be conspicuous and admitted, much will require to be done. I do not now speak of changes in the method of medical education, im. portant though these may be ; I am thinking of that improvement in diagnosis which it is in the power of every one of you to help forward. You will find in a small volume recently published by Dr. MaudsleyBody and Mind -an admirable summary of the present state of the question as to the relations of mental and bodily disease. I care not whether that book be denounced as materialistic or not, even admitting (though it is not common) that a rational meaning be attached to the word materialistic. It is more to the purpose that the method of inquiry therein indicated gives promise of good results. Whether you regard mind as a function of body-as his opponents delight to put his views - or consider mind to be a separate entity, it is clear that physical disorder can be in many cases assigned as the cause of mental disorder; and all that you have to consider as physicians is, not whether his metaphysics be correct, but whether there be any assignable limit to this mutual influence of body and mind. In the time which must pass before you have got a footing on the ladder of professional success, you could not employ yourselves more profitably than in the perusal of that small volume. If, enamoured of the subject, you pursue your investigations and read the works of Griesinger and other continental disciples of the same school, I warn you that you may find much to shock your prejudices (using the word in its original sense), but a vast deal more that will throw light on many hitherto obscure questions in pathology.

You know that hypochondriasis and melancholia are symptomatic of hepantic and gastric disorder, usually organic, sometimes, however, functional in character; that chronic rectal and pharyngeal inflammations are accompanied by peculiar and, for the most part, similar depression. Puerperal insanities have relation to special organs whose innervation is interfered with. If any of you have unhappy acquaintance with headache, you know that the locality of the pain represents a difference of cause. I might multiply examples of direct sympathies, i.e., of direct connexion between the centre and the periphery, and of reflex sympathies where organs, not in immediate contact, are nevertheless simultaneously affected through the centres, as of ovaries and stomach. The vague phrenology, or, as one might more justly call it, chorography, herein indicated, is as yet unwrought ground. In face of the localisation indicated in aphasia, we have no right to say that other similar localisations may not be hereafter recognised. The terms choleric and splenetic themselves refer to hypotheses of direct dependence of mental on visceral states; and though the hypothesis may be wrongly used, it is much more scientific in character than the flippancy with which modern witlings and pseudo-philosophers comment on doctrines which were based on a rational belief in the mutual relations of all the organs in the body. A few years ago, Professor Laycock revived in Scotland physiognomical diagnosis, or, to speak strictly, formulated and extended that method of research ; and I would, as a naturalist, recommend to you the perusal of the volume in which his physiognomical notions are summarised. I had ample opportunities of observing the practical use of the physiognomical method; and though in many respects, so far, at least, as diagnosis with a view to treatment was concerned, the exceptional far outnumbered the normal cases, I am bound to say that it was in spirit a thoroughly scientific application of zoological principles to man. And the lack of precision which I have just mentioned indicates, not error in method, but that the classification empirically adopted was in some ways not sufficiently general. I am not called on just now to criticise the indications set forth as characteristic of diathesis or constitutional tendences on the one hand, of cachexia or pathological states on the other. All that I meed say is, that the yellow colour of icterus is no more certain a sign of hepatic disorder, than complexion, hair, and skin, are of a depraved physical state, due to the degeneration of parents under evil surroundings, and ready to burst into disease. Every successful practitioner is, to some extent, guided by the evidence furnished by outward appearances ; and a surgeon of long experience relies, probably more than he himself knows, on small points which confirm or contradict the patient's statement, or perhaps suggest a different hypothesis regarding the character or cause of his affection. Distinguish, therefore, carefully; and this caution applies to more things than physiognomical diagnosis, between censure of a law and to condemnation of errors or extravagances in its application. Do not be misled by fluent talk about the impossibility of refinements so extreme as physiognomical diagnosis would require. The subject has never had a fair chance in this country. It would be as wise to expect the offspring of a cat to resemble a dog, as to look for signs of robustness in the child of phthisical parents. Malnutrition affects all the tissues of the body; but it depends on circumstances in what organ obvious, disease shall first appear. In a very valuable essay by Dr. Clouston, the Superintendent of the County Asylum at Carlisle, the relations of tuberculosis to insanity are carefully wrought out. While it is shown that monomania of suspicion is the most frequently associated with phthisis, he further makes out a case for the separation of what he calls phthisical mania, the prognosis in which is, that the sufferer will die within three or four years. He admits that the classification of forms of insanity does not present well marked lines of separation between distinct groups; and the admission is important. But it does not invalidate our classifications any more than the coincidence of hepatic, cardiac, and renal disease tends to throw doubt on the existence of either kind of physical disorder. The main feature of his essay is, that it points out the possibility of a particular form of insanity existing as a consequence of a particular kind of malnutrition of the brain. And as every viscus exerts its special influence on the blood, the malnutrition resulting from imperfect action of a viscus must vary according to the material which is thus excessive or defective in the nutritive fluid. We know that opium acts differently on the brain from belladonna ; and difference of chemical composition represents that dissimilar action. We can distinguish the poison from its symptoms, but we cannot yet tell what is the particular symptom to be ascribed to disease of a depuratory organ; we do not as yet know to which portion of the central nervous system any organ is specially related. Here, then, gentlemen, is a field of investigation in which fame may be won; and the results of successful research would tell importantly on the prevention and diagnosis of disease. Ascribing, as I do, very extensive influence to physical disease, it follows that the area of moral responsibility is proportionally diminished. I do not mean that this diminution should have, as a necessary result, in one case out of a hundred, immunity from punishment. On the contrary, punishment acts as a moral tonic, suppressing for a time the psychical symptoms of disease. But there are too many cases in which vice and crime are in the hands of the medical practitioner. He has to act the part alternately of moral instructor and of physician. A mistaken notion that the former office is beyond his sphere, often ends in his thinking his patient unsuited for any medical treatment at all ; and a catastrophe may ensue which need never have occurred, which ought to have been averted. The bronchitic patient who was lured well nigh to suicide by a persistent phantom, which disappeared, and with it the suicidal tendency, on the administration of an opiate to relieve the breathing, is a type of a large class of cases. We have, on the one hand, minor symptoms neglected; on the other, grave symptoms exaggerated ; one patient ends in an asylum, as the result of long mismanagement ; the other finds his way thither too speedily, the pronounced insanity forcing the ignorant or timid practitioner to turn over the responsibility to an asylum, cruelly and wrongfully in any case, but still more so when popular prejudice brands the lunatic with disgrace. Nor is this evil state of matters solely chargeable against the ordinary members of the profession. The Nomenclature of Diseases, a work sanctioned by the high authority of the London College of Physicians, and forwarded to every member of the profession by the Registrar-General, contains a section entitled Disorders of the Intellect, which includes six headings : Mania (acute and chronic), Melancholia, Dementia, General Paralysis, Idiocy, and Imbecility- 
a hazy classification, speciously exact, and fitly paralleled, as has been suggested, by the classification of respiratory diseases under slow, hurried, and irregular breathing.

Let me digress for one moment, to remark that the difficulty of organising in this country satisfactory clinical instruction in insanity, has much to do with this state of things. But, though the medical schools of Britain are all alike open to this censure, you are not thereby free from responsibility. The time is not far distant, I hope, when the new clinique in our immediate neighbourhood shall include wards for norvous diseases. But, meanwhile, you can do much by careful study and observation to remedy the defect. By nervous diseases, is commonly understood a chaos in which neuralgia, hysteria, fear, and insanity are included and covered by one censure ; in fact, to condemn a pain as nervous, or to call mental anxiety just nervousness, is deemed, for the most part, to fulfil the double condition of scientific precision and exhaustive treatment. Woe to the man or woman who has once been branded as nervous; let him or her retire as soon as may be to an asylum, or consult a quack doctor, for careful treatment; even human sympathy is forfeited, as a general rule, by the nervous. Gentlemen, this is a sad admission to make; it is only a slightly exaggerated statement. Never forget that these trifling ailments cannot be summarily dismissed; it requires attention to ascertain their genuineness or fanciful character; and even if they be mere fancies, laughter, rudeness, and indifference, are not the best, nor are they generous ways of dispelling them. But they are frequently the signs of unsuspected disease, which will escape detection till the time of recovery is past. Nervousness in (of all men) a London attorney was removed by the timely injunction to take a sufficient midday meal : imperfect nutrition having originated symptoms undistinguishable at first sight from those of general paralysis. Melancholy, irregular in its paroxysms, has been traced to residence in a house or district badly drained ; for, Dr. Madden notwithstanding, malaria is not simply catarrh with or without influenza. In isolated cases, errors in diet or in domestic arrangements may require some ingenuity to hunt out; but it is worth while cultivating that ingenuity when it is known how frequently external conditions, that is to say, removable causes, foster temporary diseases, which may, by neglect, become permanent organic lesions.

Such cases I hold to be socially more important than fevers or surgical accidents; for the hereditary transmission of degraded physique, and of weakened nervous system, is thereby prepared for ; and the issue, as I have shown, is serious. Let it not be said that the weakly tend to disappear by natural selection : they do in one way truly, but extinction by infertility is somewhat slow, and, before fthat has been reached, the minor degrees of impairment have been multiplied, so that each diseased man becomes, as it were, a centre of mischief, the area of which it is impossible to define.

But it is in large towns that you will find the most hideous evidence of the moral taint of disease $;$ it is in them that the most earnest practitioner will find the widest field for his philanthropic exertions. But, alas ! it is there, where the need is greatest, that the hope of success is least. Greed, laissez aller, and the worst forms of corporate and private selfishness and indifference, carefully foster disease, to the pecuniary damage of the community and the persistent moral degradation of a large section of the people. I was struck with the fact that in 1777 the mortality in Glasgow, below five years of age, was the same per cent. as now. Dr. Gairdner, to whom I mentioned this fact, startled me by saying the wonder is that it is not greater now. And his admirable paper on Defective House Accommodation as a cause of Mortality fully explains his meaning. Persistent overcrowding, defective ventilation and drainage, tend to produce and maintain a bodily state which is eminently unfavourable to the chances of life of the young. But they, at the same time, permit and foster-nay, rather directly originate - a perverted moral state, under which care for the offspring diminishes. The social question here overshadows the purely medical one; and, as statistics have been adduced to show that the mortality in Scottish towns is increasing, while in English towns it is diminishing, there is no chance that your efforts as public instructors and social leaders may soon be dispensed with. Do not imagine that this is true for towns only, or even for the lower part of towns; the same social errors are committed in every part of the country-in the best as well as the lowest districts of our large towns; the same evils have to be combated; the same line of conduct is required of you in all cases.

I do not expect that you will assent to all I have said; but to the main object of this address no exception can be taken.

I have endeavoured to make clear, by a few examples, that the medical man who trusts to his purely professional skill, and believes that having exerted that he has discharged his duty, is only, after all, a well trained tradesman, for he has not sufficient enthusiasm to be called a monomaniac. Your duty to society requires that you should use all your knowledge, not merely to heal the sick, but to better the healthy. You have learned the mutual actions of body on mind and mind on body; you are, therefore, prepared to remove or to avert disaster from either; and you are required to use this knowledge, not merely in the face of actual or impending danger, but so that the possibility of mischief may be diminished from year to year. You will not always earn substantial reward, far less fame, by your efforts ; but ours is a profession which has not always limited its work by the prospect of returns. One reward you are certain of, that of a good conscience; and the consolation of having done your best for the good of your fellow men is not to be lightly thought of.

\section{ISCHL AS A SUMMER RESIDENCE FOR CONSUMPTIVES.}

\section{BY J. HENRY BENNET, M.D.}

IN one of the interesting letters of the Vienna correspondent in a recent number of the JOURNAL, I have just read a warm recommendation of Ischl as a summer residence for British consumptives. I must, however, register a disclaimer of this opinion, founded on personal knowledge of Ischl, and of the Continent generally, in summer time. I have passed several weeks at Ischl in August and early September, and have no hesitation in saying that, lovely as it is, the heat is much too great for consumptives. This favourite watering-place is, it is true, fifteen hundred feet above the sea; but that elevation in continental Europe does not sensibly mitigate summer heat. Indeed, at the latitude of Ischl it requires, at the very least, double the elevation-one of from three to four thousand feet-to escape the extreme tropical heat of July and August.

I believe that it is now generally acknowledged by British patholo. gists that extreme heat is most pernicious in tubercular disease. Intense heat is everywhere inimical to health and to life; it tries even sound constitutions, and is still more injurious to those who are suffering from cachectic diseases, and especially from tubercular cachexia. It destroys the appetite, impairs sleep, gives rise to exhausting perspirations, and interferes with the physiological action of the lungs, liver, and intestines, thus predisposing to bilious and intestinal derangement. Are such conditions-conditions altogether antagonistic to the recuperation of vital power-to be actually courted and sought for?

Yet this is what consumptives do when they leave our temperate island for the heated mainland in midsummer. They rush into the furnace of continental midsummer heat, from which there is no escaping, except by ascending mountains to an altitude of 4000 feet or thereabouts. This can, it is true, be done in some regions, such as Switzerland, where there are various pensions and hotels at the higher mountain elevations, as in the Engadine and on the Rhigi. Indeed, to be safe in continental Europe in July and August, consumptives must seek these havens, these harbours of refuge against hot weather. No mineral waters, however salubrious and vitalising, can compensate for the absence of a cool bracing atmosphere; nor can they ever counteract the evil effects constantly produced by an amount of heat which makes life itself an ordeal, a penance, during the day, until the shades of night fall, to be endured only by living in darkened rooms in a state of semi-nudity, and by drinking buckets of lemonade and iced water.

I am fairly warranted, on my own personal experience, in stating that there is no summer climate in Europe so good for consumptives as our British insular climate, where we are constantly screened from the rays of the midsummer sun by an atmosphere full of watery vapour. I attribute in a great measure my own recovery to my having withstood the temptations of summer travel, and to my having returned home year after year. I may add that my experience with others has been idenafer yeary spring, for the last twelve years, I have had, at Mentone, where I spend the winter, to direct the movements of a considerable number of consumptives, whom I have helped on throughout their winter sojourn. Many will travel, will go to Switzerland; many are obliged to remain in the vicinity of the locality where they are to spend the ensuing winter, owing to res angusta domi; but I invariably use my influence to induce them to go to the higher mountain regions. Every autumn, when we all meet again, I find that thuse who have returned to England, and have lived there in the country, have done the best. Nearly all my best cases during ten years have been persons who have returned regularly to England, who have even there sought cool, healthy country localities, and who have gone north in our very hot weather.

In conclusion, I would remark that a knowledge of these facts does 